\title{
Neurosurgery Residency in India: Effect of COVID-19 on Residency Program
}

\author{
Himanshu Raval ${ }^{1, \oplus ~ N i h a r ~ G a u r ~}{ }^{2}$ Mona Bhatt ${ }^{3}$ \\ ${ }^{1}$ Department of Neurosurgery, Nathiba Hargovandas Lakhmichand \\ Municipal Medical College, Sardar Vallabh Bhai Patel Hospital \\ Campus, Elisbridge, Ahmedabad, Gujarat, India \\ ${ }^{2}$ Gujarat Adani Institute of Medical Sciences-Gordhan Khetsinh \\ General Hospital Genral Hospital, Bhuj, Gujarat, India \\ ${ }^{3}$ Community Health Centre Dolasa, Kodinar, Gujarat, India
}

Indian J Neurosurg 2021;1:89-90.

Till August 2020, there was a total of 22,812,491 confirmed cases of COVID-19, including 795,132 deaths, reported to WHO. ${ }^{1}$ According to Govt. of India, there was a total of 765302 active cases in India till August end. ${ }^{2}$ The condition is worsening every passing day in terms of number of active cases; although there is a high recovery rate, there exists an imbalance between demand of medical fraternity and availability of services. Hence, routine medical services have been halted, and the main focus is toward stemming the Corona pandemic. Coronavirus belongs to the reoviridae family, an enveloped RNA virus with club-shaped peplomeres on its surface and having properties of both acid-labile and acid-stable. $^{3}$

Residency in neurosurgery is considerably difficult when compared with other surgical superspecialty branches due to heavy inflow of critical patients. This is more profound in a government setup. The history of neurosurgery in India, when compared on a global scale, is relatively short. Dr. Jacob Candy started the first neurosurgical department at Christian Medical College (CMC), Vellore, in 1949 after completing his training in Canada and the United States. At that time, he only had 12 dedicated beds for neurosurgical admissions spread over various medical and surgical wards. The first residency-training program of India was started here in 1954, and the first recognized University course for M.S and later for M. Ch. in neurosurgery was begun in the year $1958 .{ }^{4}$

The 3-year neurosurgical residency (M. Ch) was started at the All India Institute of Medical Sciences (AIIMS), New Delhi, under the leadership of Prof. P.N. Tandon and Prof. A K Banerji in 1967. ${ }^{5}$ The overview of neurosurgical residency has been well described by Dr. Garg earlier. ${ }^{6}$

The major surgical exposure for residents involves trauma cases, which happen to be the first cases to start a neurosurgical career with independently as residents. Due to the

\author{
Address for correspondence Himanshu Raval, Master of \\ Surgery, Department of Neurosurgery, Nathiba Hargovandas \\ Lakhmichand Municipal Medical College, Sardar Vallabh Bhai Patel \\ Hospital Campus, Elisbridge, Ahmedabad 380006, Gujarat, India \\ (e-mail: hims02929@gmail.com).
}

meager number of neurosurgery residents as well as neurosurgeons serving the population of India, the number of patients per capita is very much high, particularly in cases of trauma. For people belonging to the low socioeconomic class, government hospitals are boon. At almost colleges, at least $50 \%$ beds are occupied with trauma cases in the neurosurgery department. Almost $1 / 3$ rd of the residents are admitted to working for more than 100 hours/week, which may be physically and mentally draining and leave little time for consolidation and assimilation of the knowledge and experience gained. ${ }^{6}$

Cold cases have their fair share also. Residents were more inclined toward surgical exposure regardless of their academic expertise. This was the scenario before COVID-19 pandemic started to unleash its fury in India, prior to April 2020 to be precise.

The overall picture after April 2020 did not turn out to be rosy for residency in terms of academic as well as surgical exposure with a view to neurosurgery residency. Hospitals in states like Maharashtra, Gujarat and Delhi, where there is major share of active cases of COVID-19 patients, had to arrange for special facilities and centers to fight the pandemic, which came at the cost of decreasing exposure to routine cases and significant decrease in trauma cases, as many hospitals had to stop their routine OPD and trauma center operations to provide special facilities. There was also a significant decrease in incidence of trauma volume. ${ }^{7}$ The overall effect result was a decrease in total number of neurosurgical cases of trauma or tumor. There was, however, one specific trend, which is rooted in the residency program, that gained traction, the surge witnessed in webinars and online academic conferences. ${ }^{8}$ Hence, we can conclude that neurosurgery residents are experiencing a more negative impact on their residency program, as the normal routine of the program has been abolished and
DOI https://doi.org/

$10.1055 / \mathrm{s}-0041-1722831$

ISSN 2277-954X.
(C) 2021. Neurological Surgeons' Society of India.

This is an open access article published by Thieme under the terms of the Creative Commons Attribution-NonDerivative-NonCommercial-License, permitting copying and reproduction so long as the original work is given appropriate credit. Contents may not be used for commercial purposes, or adapted, remixed, transformed or built upon. (https://creativecommons.org/licenses/by-nc-nd/4.0/).

Thieme Medical and Scientific Publishers Pvt. Ltd. A-12, 2nd Floor, Sector 2, Noida-201301 UP, India 
exposure to cases has decreased. These changes are more pronounced in the worst COVID-hit states like Gujarat and Maharashtra and those hospitals which have a common building to manage all kinds of emergencies, as they are more focused on the handling of COVID-19. The only positive impact to have materialized is the emergence of academic webinars. It has provided a bridge between residents across faculties from India as well as other parts of the world. But a significant difference in residency can be perceived in different parts of India even during the COVID-19 pandemic. Hospitals with separate building facilities and in less affected areas have been working without any kind of distraction in terms of case load, although preoperative workup and vigilance of residents to ensure their safety have been changed drastically. The COVID-19 swab test has become mandatory for any routine surgical procedure. Clinical examination has been done with proper precaution, and emphasis has been places on single time, high-yield examination. Outcome of emergency surgeries of COVID-19 patients have been studied and compared with that of normal patients. Although data collection is being done at nuclear level by institutes, emphasis must be put on central collection of data.

After observing the entire picture from afar, one can think about the necessity of a central governing body for neurosurgical residency and neurosurgery practice. A body that can act as apex instructor and maintain similarity of academic as well as practical aspect of residency; thus, every resident can gain similar exposure to all available opportunities. A common logbook system as well as routine periodic assessment of residency program in every institute is plausible. This system could result in a better crop of upcoming neurosurgeons. Central data provides us valuable information, and its study can derive many useful conclusions, as India has a large number of neurosurgical patients. Although its implementation seems unrealistic, all great things start from scratch. We can, therefore, build a good and efficient residency program.

\section{Funding}

None.

\section{Authors' Contributions}

H.R. helped in data acquisition and analysis, drafting, and revision of manuscript. M.B. and N.G. contributed in drafting and revision of the manuscript.

\section{Conflict of Interest}

None declared.

\section{References}

1 WHO Coronavirus Disease (COVID-19) Dashboard. Available at: https://covid19.who.int/. Accessed December 7, 2020

2 Ministry of Health and Family Welfare Government of India. COVID-19 State wise Status. Available at: https://www.mohfw. gov.in/. Accessed December 7, 2020

3 Kanungo R, ed. Ananthnarayan and Paniker's Textbook of Microbiology. 10th ed. Himayatnagar, Hyderabad: Universities Press; 2017:563-564

4 Mohanty S. Reminiscences of neurosurgery training at AIIMS, New Delhi. Neurol India 2018;66(2):298-300

5 Singh M, Sawarkar D, Sharma BS. Neurosurgery at All India Institute of Medical Sciences, a center of excellence: a success story. Neurol India 2015;63(4):589-596

6 Garg K, Deora H, Mishra S, et al. How is neurosurgical residency in India? Results of an anonymized national survey of residents. Neurol India 2019;67(3):777-782

7 Waghmare A, Shrivastava S, Date S. Effect of Covid-19 lockdown in trauma cases of rural India. International Journal of Research in Pharmaceutical Sciences 2020;11(SPL1) :365-368

8 How COVID-19 Changed Webinars. Available at: https:// www.on24.com/blog/how-covid-19-is-changing-webinars/. Accessed December 7, 2020 